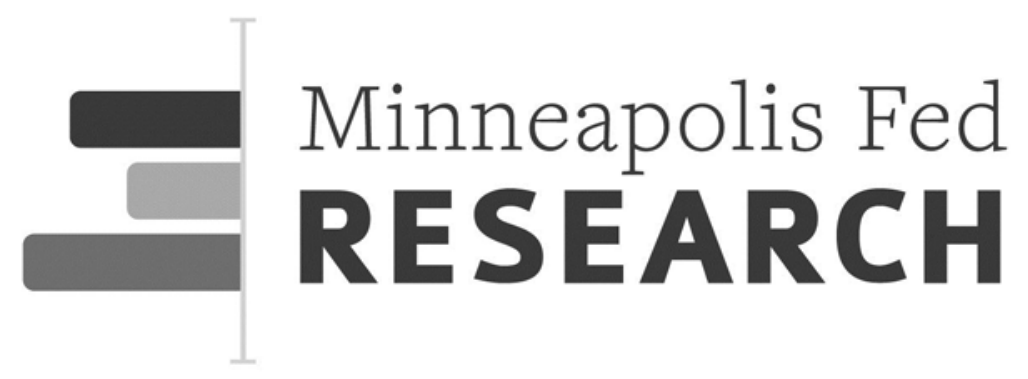

\title{
Fiscal Austerity during Debt Crises
}

\author{
Cristina Arellano \\ Federal Reserve Bank of Minneapolis \\ Yan Bai \\ University of Rochester
}

Staff Report 525

January 2016

Keywords: Sovereign default; Tax reforms; Debt crisis

JEL classification: F3

The views expressed herein are those of the authors and not necessarily those of the Federal Reserve Bank of Minneapolis or the Federal Reserve System. 


\title{
Fiscal Austerity during Debt Crises*
}

\author{
Cristina Arellano \\ Yan Bai \\ Federal Reserve Bank of Minneapolis University of Rochester
}

January 26, 2016

\begin{abstract}
This paper constructs a dynamic model in which fiscal restrictions interact with government borrowing and default. The government faces fiscal constraints; it cannot adjust tax rates or impose lump-sum taxes on the private sector, but it can adjust public consumption and foreign debt. When foreign debt is sufficiently high, however, the government can choose to default to increase domestic public and private consumption by freeing up the resources used to pay the debt. Two types of defaults arise in this environment: fiscal defaults and aggregate defaults. Fiscal defaults occur because of the government's inability to raise tax revenues. Aggregate defaults occur even if the government could raise tax revenues; debt is simply too high to be sustainable. In a quantitative exercise calibrated to Greece, we find that our model can predict the recent default, but that increasing taxes would not have prevented it. In fact, increasing taxes would have made the recession deeper because of the distortionary effects of taxation.
\end{abstract}

\footnotetext{
*The views expressed herein are those of the authors and not necessarily those of the Federal Reserve Bank of Minneapolis or the Federal Reserve System. We thank the National Science Foundation for financial support under grant 1024581. E-mail: arellano.cristina@gmail.com; yanbai06@gmail.com.
} 


\section{Introduction}

The recent European debt crisis prompted an active debate in financial and policy circles on fiscal austerity. One side of the debate considers fiscal austerity plans to be beneficial because by increasing taxes, the government can avoid a default by more easily servicing and reducing the debt. ${ }^{1}$ The other side of the debate considers fiscal austerity plans to be detrimental because higher taxes can lead to more severe recessions and a deepening of the debt crisis. $^{2}$ Here, we evaluate the interconnection between fiscal constraints and sovereign defaults in a quantitative dynamic model.

This paper constructs a dynamic model in which fiscal restrictions interact with government borrowing and default. The government faces fiscal constraints; it cannot adjust tax rates or impose lump-sum taxes on the private sector, but it can adjust public consumption and foreign debt. When foreign debt is sufficiently high, however, the government can choose to default to increase domestic public and private consumption by freeing up the resources used to pay the debt. Two types of defaults arise in this environment: fiscal defaults and aggregate defaults. Fiscal defaults occur because of the government's inability to raise tax revenues. Aggregate defaults occur even if the government could raise tax revenues; debt is simply too high to be sustainable. In a quantitative exercise calibrated to Greece, we find that our model can predict the recent default, but that increasing taxes would not have prevented it. In fact, increasing taxes would have made the recession deeper because of the distortionary effects of taxation.

The government in our model is benevolent and lacks commitment to repay the debt. It collects distortionary consumption and labor taxes, provides transfers to the private sector, decides on public consumption, and issues defaultable bonds in international financial markets. Default entails costs in terms of output and financial market access. After default, the government can renegotiate the debt by paying a recovery value. Renegotiation lifts all default costs. The price of debt compensates risk neutral lenders for the expected loss from default. Domestic agents consume private and public consumption goods, provide labor for production, pay taxes, and receive transfers from the government. The economy is subject to productivity shocks.

The government faces two constraints when deciding whether to default: the fiscal constraint and the economy's resource constraint. The fiscal constraint limits public consumption

\footnotetext{
1 "Delaying fiscal consolidation is no free lunch. It means higher debt levels. And this has real costs in the euro area where public debts are already very high." European Central Bank Executive Board member Jorg Asmussen, speaking at the Economist's Bellwether Europe Summit in London, April 25, 2013.

${ }^{2}$ Paul Krugman, "Myths of Austerity" (editorial), New York Times, July 1, 2010.
} 
to be less than tax revenues net of the international debt operations. Default can be beneficial for fiscal reasons. It relaxes the fiscal constraint and allows public consumption to be higher. The resource constraint limits public and private consumption to be less than output net of the international debt operations. Default can also be beneficial for aggregate reasons. Default relaxes the resource constraint and allows total consumption to be higher. The first takeaway from our analysis is that fiscal austerity proposals that raise taxes can help only with fiscal defaults. If defaults happen for aggregate reasons, no fiscal reform could prevent them. The second takeaway is that fiscal austerity programs that increase distortionary taxes can actually make the debt crisis worse. Raising taxes during a crisis can deepen the recession, which increases default risk especially for aggregate defaults.

We calibrate our model to Greece and use it as a laboratory in which to evaluate a fiscal austerity reform that increases taxes. The calibrated model can match the mean and volatility of the Greek spreads and in an event analysis can predict the recent Greek default. Specifically, we feed into the model the sequence of productivity shocks that leads to output dynamics as observed in Greece since 2001. The model predicts a default in 2011 and a renegotiation in 2012 with a recovery of 27\%. Recall that Greece defaulted in March 2012 and shortly after renegotiated with a recovery of $35 \%$.

With the calibrated model at hand, we perform three experiments. First, we analyze an increase in consumption taxes from the baseline of 0.15 to 0.22 . Second, we increase labor taxes from the baseline of 0.33 to 0.40 . Third, we maintain tax rates as in the baseline but allow the government to freely adjust lump sum taxes. These experiments are more aggressive versions of policies that were considered for Greece.

We find that higher tax rates increase debt sustainability. The set of debt positions for which the economy repays is larger when taxes are high than when taxes are low. The larger debt sustainability feeds into more favorable borrowing conditions. In the long run, however, the larger debt sustainability does not translate into lower default probabilities. These experiments suggest that higher taxes can alleviate a debt crisis in the short run but not in the long run.

We use our model to ask whether a fiscal reform in Greece in 2011 could have prevented the default. Through the lens of our model, we find that increasing labor or consumption taxes would not have prevented the default. In the event analysis, we unexpectedly increase tax rates in 2011 permanently, and the economy continues to default despite the larger tax revenues. The extra tax revenues are used in 2011 for higher government consumption. Moreover, increasing taxes in 2011 makes the recession deeper.

Finally, we compare the benchmark model with one in which the government does not 
have the fiscal constraint and can freely adjust lump-sum taxes. An economy with no fiscal constraint can sustain more debt and features more stable public consumption. In the long run, this economy borrows more but also defaults more, with default probabilities increasing relative to the benchmark by $1.3 \%$. In the event analysis, the default in 2011 continues to occur even after lifting the fiscal constraint permanently.

Our paper builds on the literature that studies the relation between debt crises and fiscal policy. Bi (2012) studies how fiscal policy determines debt limits that arise endogenously from dynamic Laffer curves. She finds that only long-run fiscal austerity measures can alleviate default risk. In that paper, however, default is determined by an ad hoc rule that depends only on the level of debt and other variables of the economy. Mendoza, Tesar, and Zhang (2013) study the impact of tax hikes when countries face large debt shocks and compete for capital flows using taxation. They find that for the GIIPS countries (Greece, Ireland, Italy, Portugal, and Spain) in Europe, increasing labor taxes could restore solvency when facing large debt shocks, but such a response is costly because capital flows to lower tax economies. Their paper, however, abstracts from default as an equilibrium outcome, which was a key concern for Europe.

Our paper is also related to the literature on endogenous default risk. Eaton and Gersovitz (1981) and Arellano (2008) study sovereign default that arises from high debt and low income. These papers, however, abstract from fiscal constraints. Cuadra, Sanchez, and Sapriza (2010) and Pouzo (2013) study economies with endogenous default with flexible and varying labor taxes. They find that with endogeneous default, debt is less useful for the government to smooth fluctuations, and taxes are more volatile and can become procyclical. In our paper, we focus on how the rigidity of labor taxes can induce default because of the government's inability to raise enough revenue.

\section{Model}

We consider a small open economy model with a representative firm, a continuum of consumers, and a benevolent government. The representative firm produces final output using labor $\ell$ with a production function $f(z, \ell)$. The firm faces productivity shocks that are Markov with transition matrix $\mu\left(z^{\prime} \mid z\right)$. Consumers derive utility from private consumption $c$ and public consumption $g$, and have disutility of labor $\ell$. The preferences are given by

$$
E \sum_{t=0}^{\infty} \beta^{t} u\left(c_{t}, g_{t}, \ell_{t}\right)
$$


where $\beta$ is the discount factor, $0<\beta<1$. Every period, the consumers provide labor and receive wage income $w_{t} \ell_{t}$ and dividend income $p_{t}=f\left(z_{t}, \ell_{t}\right)-w_{t} \ell_{t}$ from the firm. Consumers also pay consumption and labor taxes with tax rates $\tau_{c}$ and $\tau_{\ell}$, and receive transfers $\kappa_{t}$ from the government. ${ }^{3}$ The budget constraint for consumers is

$$
\left(1+\tau_{c}\right) c_{t}=\left(1-\tau_{\ell}\right) w_{t} \ell_{t}+p_{t}+\kappa_{t}
$$

The government purchases public goods, collects revenue from consumption and labor taxes, makes transfers to the consumers, and borrows internationally. The government faces a fiscal constraint because it cannot change tax rates and cannot levy a lump sum tax on private sectors. The fiscal constraint requires transfers to be positive, $\kappa_{t} \geq 0$. The government is active in international markets, where it borrows uncontingent bonds $b^{\prime}$ from international lenders. International financial contracts, however, have limited enforcement in that the government can default on its debt due $b$. If the government defaults, the economy receives a bad credit standing, it is excluded from international markets, and it suffers a direct productivity loss. If the economy is in bad credit standing, the government can renegotiate its debt and bargain over the debt recovery. After renegotiation, the economy regains a good credit standing, and the productivity costs are lifted. In our model, active government policies $\pi$ are a quadruple consisting of borrowing $b^{\prime}$, default and renegotiation $d$, public consumption goods $g$, and transfers $\kappa, \pi=\left\{b^{\prime}, d, g, \kappa\right\}$. Default and renegotiation decisions affect economy-wide productivity. Let $\tilde{z}=z(h, d)$ denote the effective productivity of the economy such that $\tilde{z}<z$ when the government defaults and the economy is in bad credit standing without renegotiating and $\tilde{z}=z$ otherwise.

A domestic competitive equilibrium is a set of allocations $\{c, \ell\}$ such that given the government's policies $\pi$, consumers and the representative firm optimize. The domestic competitive equilibrium is characterized by the optimal consumption-leisure choice condition

$$
\frac{u_{\ell}}{u_{c}}=\frac{\left(1-\tau_{\ell}\right)}{\left(1+\tau_{c}\right)} f_{\ell}(\tilde{z}, \ell)
$$

and the budget constraint (1).

\footnotetext{
${ }^{3} \mathrm{~A}$ stark assumption we make for computation reasons is that households do not directly participate in financial markets. Households can, however, smooth their utility with their choice of labor and also with government transfers $\kappa_{t}$
} 


\subsection{Recursive Problem}

We now set up the optimal policy program for the government. We consider a Markov equilibrium. The government starts each period with a state $s$ that consists of the productivity shock $z$, the debt due $b$, and the credit standing $h, s=\{z, b, h\}$. The credit standing is a binary variable and encodes a past default or renegotiation such that $h=0$ when the credit standing is good and $h=1$ when the credit standing is bad. The government chooses optimal policy $\pi=\left\{b^{\prime}, d, g, \kappa\right\}$ to maximize the utility of consumers, taking as given the bond price and recovery functions $q\left(z, b^{\prime}\right)$ and $\phi(z, b)$.

The recursive problem of the government can be formulated directly in terms of choosing allocations in addition to choosing public consumption, borrowing, and default policies as the government internalizes the competitive equilibrium conditions.

A government in good credit standing chooses first to repay or default on its debt, as follows:

$$
v(z, b, h=0)=\max _{d \in\{0,1\}}\left\{(1-d) v^{r}(z, b, h)+d v^{d}(z, b, h)\right\},
$$

where $d=1$ denotes default and $d=0$ denotes repay. If the government repays, the credit standing next period is good, $h^{\prime}=0$. Here, the government chooses private and public consumption, labor, and borrowing:

$$
v^{r}(z, b, h)=\max _{c, g, \ell, b^{\prime}} u(c, g, \ell)+\beta E v\left(z^{\prime}, b^{\prime}, h^{\prime}=0\right)
$$

subject to the economy-wide resource constraint

$$
c+g \leq f(\tilde{z}, \ell)+q\left(z, b^{\prime}\right) b^{\prime}-b
$$

the fiscal constraint

$$
\tau_{\ell} f_{\ell} \ell+\tau_{c} c-b+q\left(z, b^{\prime}\right) b^{\prime} \geq g
$$

and the private sector optimality condition (2). Transfers are then defined as $\kappa=\tau_{\ell} f_{\ell} \ell+\tau_{c} c-$ $b+q\left(z, b^{\prime}\right) b^{\prime}-g$. The fiscal constraint (6) summarizes the fiscal limitations of the government from transferring resources to and from the private sector. Mechanically, the government can freely transfer positive net new borrowing $q\left(z, b^{\prime}\right) b^{\prime}-b>0$ by using transfers $\kappa$. The government cannot, however, extract more resources from the private sector beyond those obtained from tax revenues $\tau_{\ell} f_{\ell} \ell+\tau_{c} c$.

The bond price schedule $q\left(z, b^{\prime}\right)$, described below, compensates the loss for lenders in case of default and depends on the current shock and the borrowing level. The government takes 
as given the bond price schedule.

If the government defaults, it does not have to pay the debt due, cannot borrow, and the credit standing becomes bad next period. Here, the government chooses the labor, private, and public consumption to maximize the value

$$
v^{d}(z, b, h)=\max _{c, g, \ell} u(c, g, \ell)+\beta E v\left(z^{\prime}, b^{\prime}=b, h^{\prime}=1\right)
$$

subject to the resource and fiscal constraints

$$
c+g \leq f(\tilde{z}, \ell)
$$

the fiscal constraint

$$
\tau_{\ell} f_{\ell} \ell+\tau_{c} c \geq g
$$

and the implementability condition from the private sectors (2).

A government with a bad credit standing has the option to renegotiate and pay the recovery $\phi(z, b)$. When credit is bad, $h=1, d=0$ indicates renegotiation and $d=1$ indicates no renegotiation. During renegotiation the productivity costs are lifted and the government's credit switches to good the following period. Taking as given the recovery function, the government chooses whether to renegotiate:

$$
v(z, b, h=1)=\max _{d \in\{0,1\}}\left\{(1-d) v^{g}(z, b, h)+d v^{d}(z, b, h)\right\}
$$

The renegotiating value satisfies

$$
v^{g}(z, b, h)=\max _{c, g, \ell} u(c, g, \ell)+\beta E v\left(z^{\prime}, b^{\prime}=0, h^{\prime}=0\right)
$$

subject to the resource constraint,

$$
c+g \leq f(\tilde{z}, \ell)-\phi(z, b)
$$

the fiscal constraint

$$
\tau_{\ell} f_{\ell} \ell+\tau_{c} c-\phi(z, b) \geq g
$$

and the implementability condition from the private sectors (2). If the government does not renegotiate, it gets a value equal to the value of defaulting, $v^{d}(z, b, h=1)=v^{d}(z, b, h=0) .{ }^{4}$

\footnotetext{
${ }^{4}$ Introducing non-zero recovery and renegotiation is not of substance for studying fiscal constraints. Nevertheless, recoveries in the data are sizable, on average $60 \%$, and hence quantitatively important for
} 


\subsection{Bond Price and Recovery}

International lenders are risk neutral and competitive and have a constant opportunity cost of lending $r$. The bond price schedule compensates all losses due to future default,

$$
q\left(z, b^{\prime}\right)=\frac{1}{1+r} E\left[\left(1-d\left(z^{\prime}, b^{\prime}\right)\right)+d\left(z^{\prime}, b^{\prime}\right) \xi\left(z^{\prime}, b^{\prime}\right)\right] .
$$

where $\xi$ is the discounted expected recovery rate depending on future renegotiation,

$$
\xi(z, b)=\frac{1}{1+r} E\left[\left(1-d\left(z^{\prime}, b\right)\right) \phi\left(z^{\prime}, b\right)+d\left(z^{\prime}, b\right) \xi\left(z^{\prime}, b\right)\right] .
$$

The bond price summarizes that in repayment states tomorrow where $d\left(z^{\prime}, b^{\prime}\right)=0$, the government pays one unit for every bond borrowed. In default states tomorrow where $d\left(z^{\prime}, b^{\prime}\right)=1$, the government does not pay anything, but in present value it pays the value of the recovery $\xi\left(z^{\prime}, b^{\prime}\right)$. The recovery present value in turn satisfies the functional equation (10) that depends on future decisions to renegotiate. The value of the recovery encodes that in states with renegotiations $d\left(z^{\prime}, b\right)=0$, the government pays the recovery $\phi\left(z^{\prime}, b\right)$.

During renegotiation, the government bargains with a committee of lenders over the recovery $\phi$ with Nash bargaining,

$$
\phi \in \operatorname{argmax}\left[v^{g}(z, b, h=1 ; \phi)-v^{a u t}(z)\right]^{\alpha} \phi^{1-\alpha},
$$

where $\alpha$ is the bargaining power of the government. In case of renegotiation failure, lenders get zero and the economy gets $v^{\text {aut }}(z)$. This value encodes that with renegotiation failure the government is in autarky forever and the economy faces the productivity costs from default. $v^{\text {aut }}(z)$ is the solution to a problem similar to that in (7) but with a continuation value that is equal to the default value thereafter.

We now define the equilibrium.

Definition 1. A Markov recursive equilibrium is a set of policies for the government $\pi(s)=$ $\left\{b^{\prime}(s), d(s), g(s), \kappa(s)\right\}$, private allocations $c(s)$ and $\ell(s)$, and bond price and recovery functions $q\left(z, b^{\prime}\right)$ and $\phi(z, b)$ such that

1. Taking as given the bond price and recovery functions, the government policies and private allocations solve (3) and (8).

2. The bond price and recovery functions satisfy (9) and (11).

studying default events. 


\subsection{Fiscal and Aggregate Defaults}

Default allows the government to avoid paying the debt and have more resources for domestic consumption. In fact, defaulting on debt $b$ is optimal only if under no default, the economy must experience capital outflows, $-b+q\left(z, b^{\prime}\right) b^{\prime}<0$. In this model, however, default relaxes two constraints: the economy-wide resource constraint and the fiscal constraint. An important aspect of our analysis is to evaluate whether default happens mainly to relax the fiscal constraint or the economy-wide resource constraint, which we label as fiscal default or aggregate default, respectively.

A fiscal default happens because it is too costly to satisfy the fiscal constraint if debt is to be repaid. Recall that the fiscal constraint limits the government from transferring resources from the private sector to the public sector, since tax rates are fixed and lump-sum taxes are not allowed. In this context, if the government has a large enough level of debt such that rolling it over is not possible, it must cut public consumption enough to service the debt. Such a reduction in public consumption might be too costly, in which case default is preferable. Fiscal defaults can be prevented if the government could raise more tax revenues by increasing tax rates.

The second class of default is an aggregate default, which is the type of default commonly analyzed in the literature of sovereign default (Arellano (2008)). An aggregate default happens because it is too costly to satisfy the resource constraint if debt is to be repaid. Here, default is preferred to avoid a reduction in both private consumption and public consumption needed to service the debt. During aggregate defaults, increasing tax revenues is of no use in preventing defaults. In fact, increasing tax rates will lead to more defaults because of the larger distortions and lower output that result from the high tax rate.

We define a default as fiscal if it happens because of the fiscal constraint (6) and a default as aggregate if it happens even when the fiscal constraint is lifted. Formally, for each state $\{z, b\}$ when $h=0$, we resolve program (3) without imposing the fiscal constraint (6) for this period only. In future periods, we assume the fiscal constraint is satisfied as encoded in the continuation value function. We label the resulting default decision from this experiment as $d_{a}(z, b)$. If the original default decision is equal to the default decision from this experiment, such default is aggregate. If the original default decision is changed with the experiment, then such default is fiscal:

$$
\begin{aligned}
& \text { Fiscal Default : } \quad d(z, b)=1 \text { and } d_{a}(z, b)=0 \\
& \text { Aggregate Default }: \quad d(z, b)=1 \text { and } d_{a}(z, b)=1
\end{aligned}
$$




\section{Quantitative Analysis}

We now analyze the quantitative implications of the model. We calibrate the model to Greek data and show that our model can predict the recent default in Greece. Our model predicts that increasing consumption or labor taxes would not have prevented the default. Nevertheless, if the Greek government had been able to use lump-sum taxes, the default could have been prevented.

\subsection{Parameterization}

We assume the production function of the economy is given by $f(z, \ell)=z \ell^{\theta}$ with a labor share parameter equal to $\theta$. The utility function is

$$
u(c, g, \ell)=\frac{\left(c-\frac{\ell^{1+1 / \nu}}{1+1 / \nu}\right)^{1-\sigma}-1}{1-\sigma}+\frac{g^{1-\sigma}}{1-\sigma}
$$

where $\sigma$ is the risk aversion parameter and $\nu$ is the Frisch elasticity. We choose $\sigma=2, \nu=2$, and $\theta=0.67$, as common in the macroeconomics literature. We take the consumption tax rate $\tau_{c}=0.15$ and labor tax rate $\tau_{\ell}=0.33$ from the effective tax rates that Mendoza, Tesar, and Zhang (2013) found for Greece. These are very similar to the average across GIIPS countries. We set the annual real interest rate to $r=2 \%$. This estimate comes from the average 1-year German nominal yield of $4 \%$ minus a $2 \%$ expected inflation. We assume the productivity shock $z$ follows an $\mathrm{AR}(1)$ process,

$$
\log \left(z_{t}\right)=\rho \log \left(z_{t-1}\right)+\sigma_{z} \epsilon_{t}
$$

Given the preferences in (13), labor supply is a simple function of productivity $\ell(z)=$ $\left.\left(\frac{\left(1-\tau_{\ell}\right) \theta z}{\left(1+\tau_{c}\right.}\right)\right)^{1 /(1+\nu-\theta)}$, which implies that output is simply a function of productivity $y(z)=$ $z \ell(z)$. We set $\rho=0.9$ and calibrate $\sigma_{z}$ such that the model reproduces the standard deviation of Greek GDP of $11.5 \%$. This volatility of output is computed from Greek annual detrended GDP data since 1990 from the World Development Indicators. We discretized the productivity process into an 11 Markov chain using a quadrature procedure.

The productivity loss from default follows the functional form in Arellano (2008). Effective productivity after default is $\tilde{z}=\left\{\begin{array}{l}(1-\lambda) E(z) \text { if } z \geq(1-\lambda) E(z) \\ z \text { otherwise }\end{array}\right\}$.

We calibrate three parameters: the productivity loss after default $\lambda$, the discount factor $\beta$, and the bargaining power of the government $\alpha$ such that the model reproduces the mean 
spread and public debt service relative to output in Greece of $4.8 \%$ and $6.0 \%$, respectively, and the historical average recovery rate of $60 \%$. Government spreads are from the Global Financial Database on 10-year bonds and relative to 10-year German bonds. Public debt service is measured as interest expenses from public debt from the World Development Indicators. Recoveries are those reported in Cruces and Trebesch (2013). Table 1 summarizes the parameter values.

Table 1: Calibration

$\left.\begin{array}{lll}\hline & \text { Value } & \text { Target } \\
\hline \text { Output cost after default } & \lambda=0.01 \\
\text { Borrowers' discount factor } & \beta=0.72 \\
\text { Bargaining power } & \alpha=0.12\end{array}\right\}$\begin{tabular}{l} 
Mean spread \\
Debt service \\
Recovery rate \\
\hline
\end{tabular}

\subsection{Default Sets and Decision Rules}

Before showing the quantitative results, we find that it is useful to analyze the decision rules in the model. We first present default sets and repayment sets. For the case when credit is good, $h=0$, the state space $\{z, b\}$ can be divided into states where default is chosen, $d(z, b)=1$, and states where repayment is chosen, $d(z, b)=0$. The solid line in Figure 1 divides the state space into these two sets. The government is more likely to default when it has large debt or lower productivity.

We also subdivide the default set into fiscal defaults and aggregate defaults, defined in (12). Aggregate defaults happen when debt is sufficiently high or productivity sufficiently low. Here, the government defaults even if the fiscal constraint is lifted for one period. The idea is that repayment is too costly in these states because private and public consumption would have to be decreased too much in order to service the debt. The figure also shows that fiscal defaults happen for smaller levels of debt and higher levels of productivity. Here, the government is defaulting because of the fiscal constraint; if the constraint could be lifted and the government could transfer more resources from the private sector to the public sector, then the default would be avoided.

In Figures 2 and 3, we plot the decision rules for public consumption, private consumption, and transfers as a function of debt $b$ relative to income when productivity is at its median and credit standing is good. Figure 2 shows that public consumption declines with debt because servicing a larger amount of debt requires a reduction in public consumption. As 


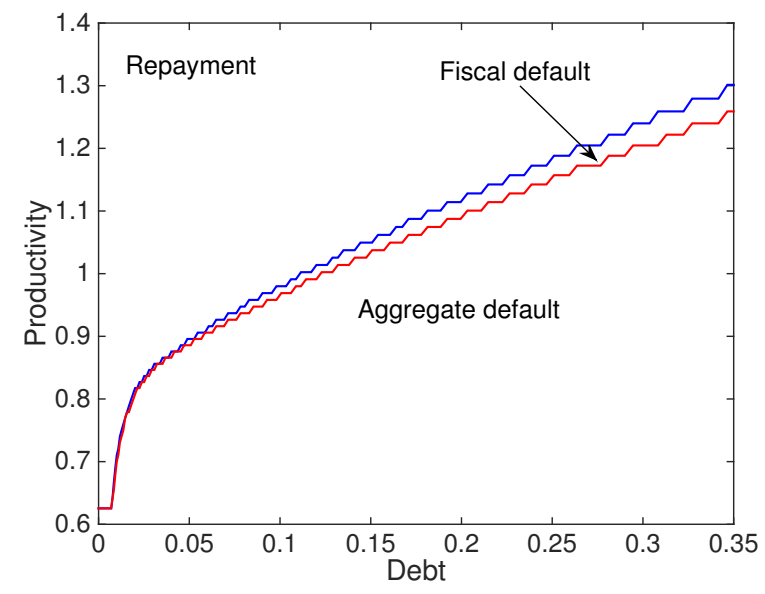

Figure 1: Default Sets

debt increases, the fiscal constraint starts to bind, which causes public consumption to decline at a faster rate with debt. When debt is sufficiently high, default is preferred. At the debtdefault threshold, public consumption jumps up despite the decline in tax revenues due to lower output in default. The relatively higher public consumption reflects the fact that the government is no longer servicing the debt. Public consumption is flat thereafter.

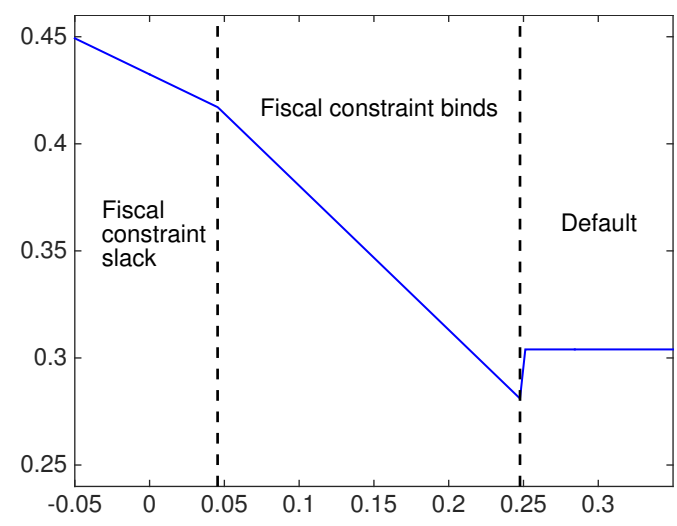

Figure 2: Public Consumption

Figure 3 shows that private consumption also decreases with debt when the fiscal constraint is not binding. When debt is small, the government borrows from abroad and transfers resources to the private sector. When debt is zero, government transfers are about $1.5 \%$ of output. As debt increases, private consumption falls because the government reduces transfers in order to service a larger stock of debt. When transfers reach zero, the fiscal constraint binds, and private consumption remains constant as a function of debt. When the government defaults, private consumption falls because of lower output associated with default. 

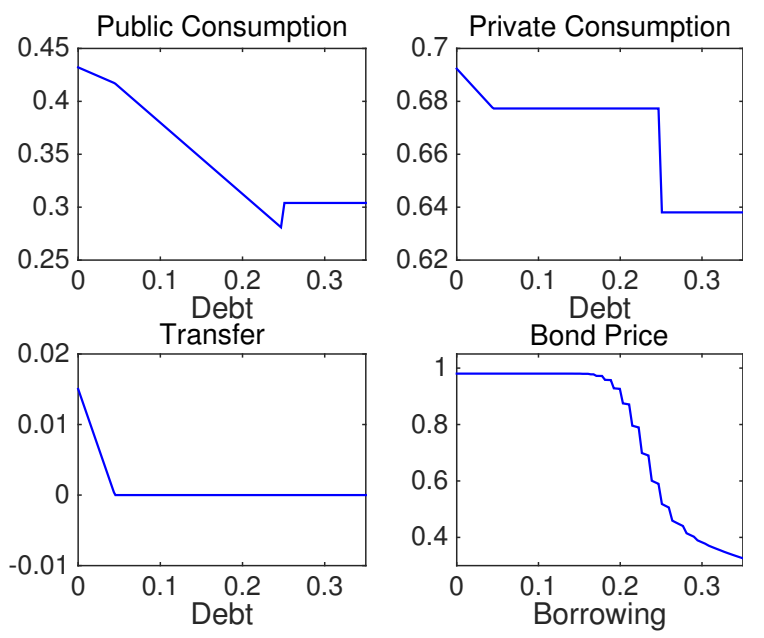

Figure 3: Policy Rules

\subsection{Benchmark Model and Greek Default}

We now present the simulation results. We present long-run averages and simulate a default event that resembles the one from Greece.

Table 2 shows means and standard deviations of the variables of interest in the long-run distribution of the benchmark model and compares them with those of Greece. The average spread is $4.2 \%$, which is similar to the average Greek spread of $4.8 \%$. Default probabilities are larger than spreads and are equal to $8.5 \%$ because of recovery. The average recovery of $60 \%$ equals the historical average recovery rate across defaults since 1980 . Debt service relative to output equals $5.6 \%$ on average, close to the data in Greece of $6.0 \%$. In our model, the country always renegotiates the period after default.

In terms of volatilities, the model is calibrated such that it generates the volatility of output. Spread volatility in our model is $2.5 \%$ lower than the $8 \%$ in the data. One reason for the lower volatility is that in the model, spreads are conditional on the country not defaulting. Private and public consumption in the model are as volatile as output. In the data, private consumption is as volatile as output, whereas public consumption is less volatile than output.

We now conduct an event analysis. We feed into the model a sequence of shock realizations such that the model's output resembles the one observed in Greece since 2001. We then compare the resulting default decisions and spread series that the model generates with those in the data. The black lines in Figure 4 correspond to the time series for output and spreads for Greece. In 2011, Greek GDP decreased to about $15 \%$ below trend and the interest spread increased by $12 \%$. In March 2012, Greece defaulted. The blue lines are the 
Table 2: Business Cycle Statistics

\begin{tabular}{lcc}
\hline & Data & Model \\
\hline Means & & \\
Spread & 4.8 & 4.2 \\
Debt Service & 6.0 & 5.6 \\
Recovery & 60 & 60 \\
\hline Std. Deviations & & \\
Output & 11.5 & 11.2 \\
Spread & 8.0 & 2.5 \\
Public Consumption & 0.8 & 1.1 \\
Private Consumption & 1.0 & 1.0 \\
& &
\end{tabular}

Standard deviations for public and private consumption, and debt service are reported relative to that of output. Mean debt service is reported relative to output.

model-simulated series. The productivity series chosen allow the model to match closely the output fluctuations in Greece. The model predicts the default in Greece, but as happening in 2011. In anticipation of such default, the model predicts a rise in spreads. The model, however, generates a more modest rise in spreads than the one observed in the data. In our model, the economy renegotiates the debt the following period in 2012. In the data, the renegotiation occurs during 2012 as well. The recovery rate in our model is $27 \%$, which is much lower than the calibrated average level of $60 \%$ because the recession is deep and recoveries are endogenously lower in recessions. The recovery rate in our model is somewhat lower than the estimates for Greece of 35\% in Zettelmeyer et al. (2013).
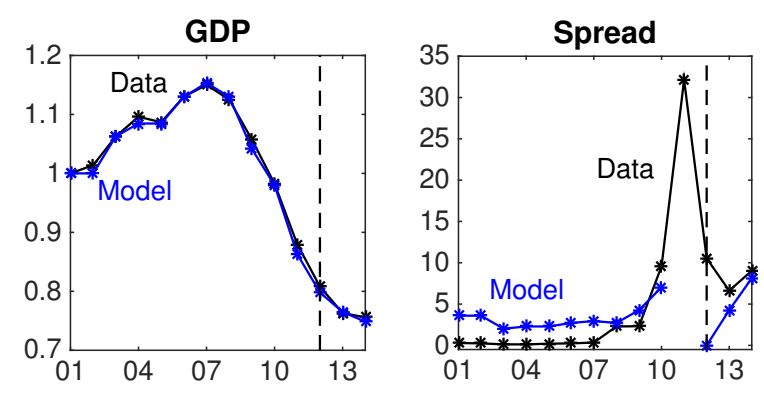

Figure 4: Greek Crisis: Data and Model

An important aspect of the Greek default was the large bailout programs implemented by the European Commission, European Central Bank, and the International Monetary Fund, as well as their efficacy in containing the crisis. Our model abstracts from bailouts per se, but in this event analysis, we can compute the reduction in debt needed to avoid the default. 
We find that if debt were reduced by $44 \%$ in 2011, the default would have been avoided completely. That is, if $44 \%$ of the debt in 2011 would have been forgiven, then the economy would have avoided the default not only in 2011, but also through 2014. In our model, the reduction of debt happens after renegotiation and with a larger magnitude of $73 \%$.

\subsection{Experiments: Effects of Fiscal Austerity}

A heated discussion surrounding the Greek debt crisis is whether Greece should have adopted an austerity plan that increases taxes in order to service the debt and avoid the default. Our model provides a laboratory in which to study the impact of increases in taxes. We use the model to conduct three counterfactual experiments. In the first one, we increase the consumption tax from 0.15 to 0.22 while keeping the labor tax constant. In the second one, we increase the labor tax from 0.33 to 0.40 while keeping the consumption tax constant. (These experiments constitute larger changes than the ones considered in different proposals.) Finally, as a reference model, we consider an economy without a fiscal constraint in which we maintain the tax rates as in the benchmark, but the government can freely adjust lump-sum taxes and transfers. This reference model gives the best chance for avoiding the default with a change in taxation. In these experiments, we keep all other parameters as in the benchmark model. We analyze the effects of these changes in tax policies on decision rules, long-run outcomes, and the default event.

Let us first consider the experiments in which the economy has a higher consumption tax rate. Higher taxes shrink default sets. Figure 5 compares the default set in the model with higher consumption taxes with the benchmark model. The figure shows that with higher taxes, the government can sustain more debt for every productivity level without defaulting. The smaller default sets with higher taxes imply that bond price schedules in the economy with higher taxes are more lenient, as shown in Figure 6. Higher taxes also lead to higher public consumption for every debt level, as illustrated in Figure 6. Moreover, higher taxes shrink the set of debt for which the fiscal constraint is binding, as seen in the smaller range of steeply declining public consumption.

Increasing labor taxes in the benchmark model has similar effects on default sets and decision rules as increasing consumption taxes. Finally, when the government can freely adjust lump-sum taxes, the distortions from the fiscal constraint are removed and only aggregate defaults remain. With lump-sum taxes, default sets shrink, bond prices become more lenient, and the declines in private consumption and public consumption with debt are less steep.

Table 3 presents long-run average statistics from these three experiments and compares them with the benchmark model. Economies with higher consumption or labor tax rates 


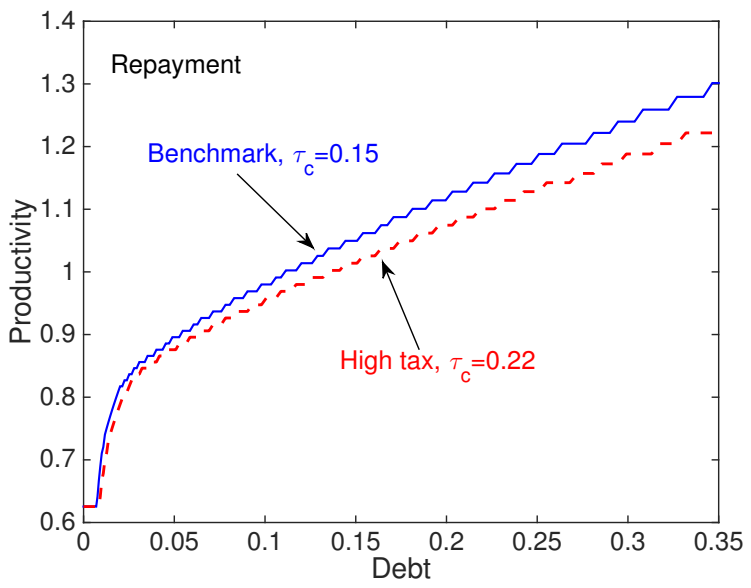

Figure 5: Default Set and Taxes
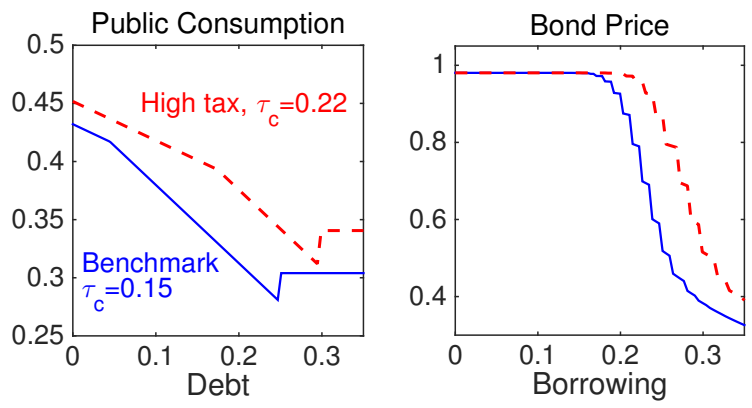

Figure 6: Policy Rules and Taxes 
have similar average default probabilities and spreads but can sustain larger levels of debt. For a given level of debt, higher tax rates lower default probabilities and spreads, as seen in the decision rules, but in the long run the debt level increases. The volatilities of spreads and private and public consumption are also similar in economies with higher consumption or labor taxes.

The long-run averages for the reference economy, in which the government can freely change lump-sum taxes and transfers, displays more differences. This economy has higher default probabilities, spreads, and levels of debt than in the benchmark model, while delivering lower volatility in public consumption and equal to that of private consumption. This economy features the smallest default set of all economies and the most lenient price functions. In the long run, however, the economy borrows more and displays larger default probabilities and spreads.

Table 3: Long-Run Statistics across Experiments

\begin{tabular}{lcccc}
\hline & $\begin{array}{c}\text { Bench } \\
\tau_{c}=0.15\end{array}$ & $\begin{array}{c}\text { High } \tau_{c} \\
\tau_{c}=0.22\end{array}$ & $\begin{array}{c}\text { High } \tau_{L} \\
\tau_{c}=0.15\end{array}$ & $\begin{array}{c}\text { No fiscal } \\
\text { constraint }\end{array}$ \\
& $\tau_{L}=0.33$ & $\tau_{L}=0.33$ & $\tau_{L}=0.40$ & \\
\hline Means & 8.5 & 8.6 & 8.3 & 9.8 \\
Default prob & 4.2 & 4.3 & 4.1 & 4.5 \\
Spread & 5.6 & 6.8 & 6.7 & 7.8 \\
Debt service & & & & \\
Std. Deviations & 2.5 & 2.6 & 2.4 & 2.4 \\
Spread & 1.1 & 1.1 & 1.1 & 1.0 \\
Public consumption & 1.0 & 1.0 & 1.0 & 1.0 \\
Private consumption & 1.0 & & & \\
\hline
\end{tabular}

A comparison across these economies casts doubt that fiscal austerity proposals that raise taxes would reduce the incidence of defaults in the long run. Within the context of our model, fiscal austerity proposals increase debt sustainability because the government has more revenues with which to service the debt. Nevertheless, it is precisely this larger debt capacity that leads to more default in equilibrium. Faced with more lenient bond price schedules, governments borrow more and in equilibrium do not change their default probabilities.

We now analyze the effects of increasing taxes unexpectedly in the Greek event. The specific question we ask is whether the Greek default could have been avoided if Greece had implemented a fiscal austerity program that raised taxes. Specifically, we repeat the event analysis described above in the benchmark model, but in 2011 we raise either consumption taxes or labor taxes, or we allow lump-sum taxes and check whether such a reform could 
have prevented the default. The change in taxation in 2011 is unexpected and permanent.
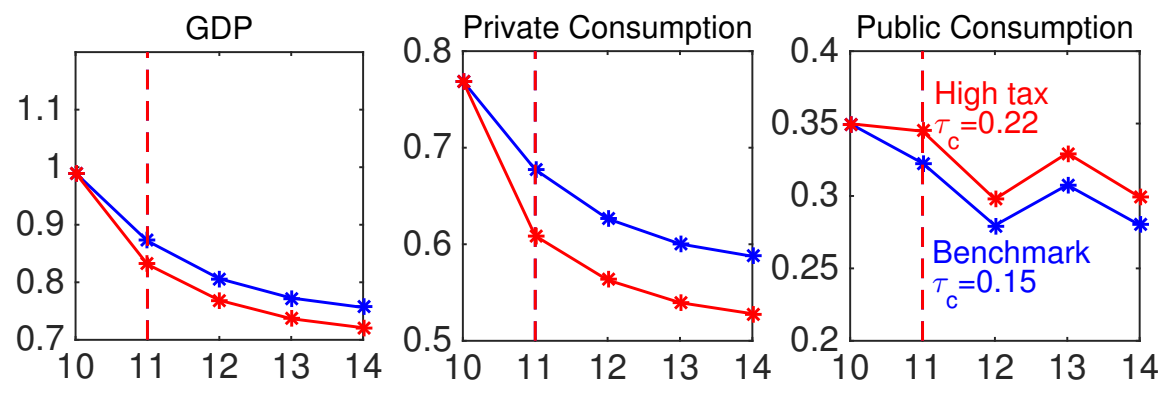

Figure 7: Default Event and Taxes

Our model predicts that neither increasing consumption taxes from 0.15 to 0.22 nor increasing labor taxes from 0.33 to 0.40 in 2011 would have prevented the default. In these two experiments, the model continues to predict a default in 2011. Debt is just too high and productivity is too low for such a reform to contain the default.

Figure 7 shows the time paths for output, public and private consumption, and transfers starting in 2010 for the benchmark model and for the experiment in which consumption taxes permanently increase in 2011. Large distortionary taxes lower GDP in the path. Private consumption falls because of lower output and a larger tax bill. Tax revenue increases, which raises government consumption relative to the benchmark.
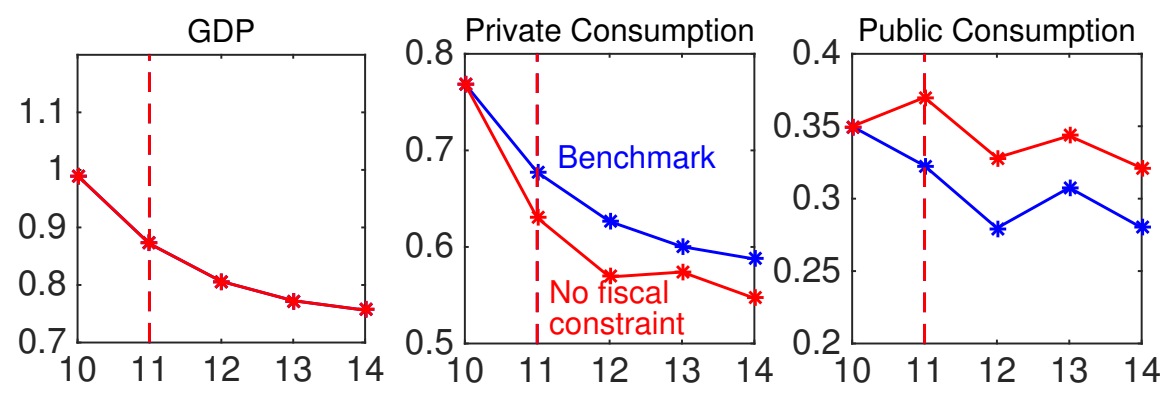

Figure 8: Default Event without Fiscal Constraint

We now consider the experiment that in 2011, the fiscal constraint is lifted permanently. With this reform, all fiscal defaults are eliminated, but the model continues to predict an aggregate default in 2011. Figure 8 illustrates the time paths for the variables of interest in this experiment relative to the benchmark. GDP is unchanged because the shocks and tax rates are as in the benchmark model. Private consumption falls and public consumption increases because the government optimally want to tilt resources toward the public sectors. Public consumption is more constant over time when the government does not face the fiscal constraint. 
These experiments cast doubt on the thesis that Greece could have avoided its default by increasing tax revenue. Through the lens of our model, we find that Greece defaulted because its debt was too large and the recession too deep.

\section{Conclusion}

This paper developed a dynamic model of borrowing and default in which fiscal constraints can induce governments to default. By defaulting, the government can increase domestic absorption. We show that increasing tax rates increases debt sustainability because it relaxes the government's fiscal constraint. In the long run, however, the government borrows more and default risk rises due to larger debt.

We parameterized the model to Greece and found that the model can predict the recent default. We also found that increasing consumption or labor taxes would not have prevented the default. In our model, the default occurs because debt was too large and the downturn too severe.

\section{References}

[1] Arellano, Cristina. 2008. Default Risk and Income Fluctuations in Emerging Economies. American Economic Review, 98(3): 690-712.

[2] Bi, Huixin. 2012. Sovereign Default Risk Premia, Fiscal Limits, and Fiscal Policy. European Economic Review, 56(3): 389-410.

[3] Cruces, Juan J., and Christoph Trebesch. 2013. Sovereign Defaults: The Price of Haircuts. American Economic Journal: Macroeconomics, 5(3): 85-117.

[4] Cuadra, Gabriel, Juan M. Sanchez, and Horacio Sapriza. 2010. Fiscal Policy and Default Risk in Emerging Markets. Review of Economic Dynamics, 13(2): 452-469.

[5] Eaton, Jonathan, and Mark Gersovitz. 1981. Debt with Potential Repudiation: Theoretical and Empirical Analysis. Review of Economic Studies, 48(2): 289-309.

[6] Mendoza, Enrique, Linda Tesar, and Jing Zhang. 2013. Saving Europe? The Unpleasant Arithmetic of Fiscal Austerity in Integrated Economies. Working paper, University of Pennsylvania. 
[7] Pouzo, Demian. 2013. Optimal Taxation with Endogenous Default under Incomplete Markets. Working paper, University of California Berkeley.

[8] Zettelmeyer, Jeromin, Christoph Trebesch, and Mitu Gulati. 2013. The Greek Debt Restructuring: An Autopsy. CESifo Working Paper No. 4333. 